\title{
Praxis y Ética en Psicología Comunitaria: Representaciones Sociales de Usuarias y Usuarios de Programas Comunitarios en la Región Metropolitana
}

\author{
Praxis and Ethics in Community Psychology: Social \\ Representations of Clients of Community Programs \\ in the Metropolitan Region
}

\author{
Jorge Castillo y María Inés Winkler \\ Universidad de Santiago de Chile
}

\begin{abstract}
La psicología comunitaria chilena ha experimentado una evolución que la ha situado como referente en las prácticas institucionales de intervención psicosocial. Esto ha implicado la normalización de las intervenciones, abandonando algunos preceptos que fundaran la disciplina, en un contexto carente de indicaciones éticas para el área. Como una forma de perfilar las prácticas disciplinares actuales y sus implicaciones éticas, se investigaron las representaciones sociales sobre la praxis profesional en usuarios/as de programas estatales y ONG, desde 4 entrevistas participativas a 32 usuarios/as. Se utilizaron herramientas del análisis del discurso. Los resultados muestran una fuerte valoración del vínculo profesional-usuario/a, un fortalecimiento progresivo desde el trabajo individual, dependencia de el//la profesional y una serie de prácticas consideradas correctas e incorrectas por los/as usuarios/as.

Palabras clave: psicología comunitaria, praxis, ética, representaciones sociales, discursos.

Chilean community psychology has undergone an evolution that has positioned it as a reference in the institutional practices of psychosocial intervention. This has involved the standardization of interventions, resulting in the abandonment of some of the founding precepts of the discipline, in a context lacking ethical indications for the field. As a way of outlining the current disciplinary practices and their ethical implications, social representations of professional practice between clients of Government and NGO social programs were investigated, through the realization of 4 participatory interviews with 32 clients. Discourse analysis tools were used. The results show a strong appreciation of the relationship between client and professional, a progressive strengthening from individual work, professional dependence, and a series of correct and incorrect actions as perceived by the client.
\end{abstract}

Keywords: community psychology, practice, ethics, social representations, discourses.

No se puede considerar que en una sociedad se es libre cuando lo que se llama diálogo solo puede ocurrir entre aquellos que dicen lo mismo o hablan con la misma voz.

Maritza Montero

Jorge Castillo Sepúlveda, Universidad de Santiago de Chile, Santiago, Chile.

María Inés Winkler, Universidad de Santiago de Chile, Santiago, Chile.

La correspondencia relativa a este artículo debe ser dirigida a María Inés Winkler, Escuela de Psicología, Universidad de Santiago de Chile, Ecuador 3650, $3^{\text {er }}$ piso, Estación Central, Santiago, Chile. E-mail: maria.winkler@usach.cl Esta publicación reporta resultados del tercer módulo del proyecto de investigación FONDECYT N 1080528: Cuestiones Éticas en la Práctica, Investigación y Formación en Psicología Comunitaria. La investigadora responsable es la Dra. María Inés Winkler.

Agradecemos a las mujeres, hombres y adolescentes que participaron en esta investigación, así como también al Ps. Mariano Ruperthuz por su colaboración. 


\section{Introducción}

A mediados del siglo XX emergía una forma de hacer psicología que integraba ideas y metodologías emergentes desde campos afines, pero diversos, fortaleciéndose progresivamente como una disciplina fundamentada en la acción y reflexión -la praxis- de profesionales concebidos/as como agentes de cambio, generativos/as y reflexivos/as (Dokecki, 1992; Montero, 2004). Desde la sociología militante, la investigaciónacción participativa y el modelo de educación popular, la psicología comunitaria se constituía con una clara orientación respecto al modo de abordar problemáticas psicosociales, implicando y explicitando los procesos políticos involucrados en la reproducción de las injusticias sociales y en la construcción transformadora de las comunidades más pobres y marginadas (Montero, 2003). Si bien fue en Norteamérica donde, desde la preocupación por constituir un modelo de salud mental centrado en la comunidad y cuestionando las definiciones clásicas del rol del psicólogo, fue bautizada esta nueva rama de la psicología ${ }^{1}$, en Latinoamérica, "sin apelar a la denominación, pero con un claro adelanto metodológico" (Montero, 1984, p. 389), desde fines de la década del cincuenta se habían realizado aisladamente desarrollos comunitarios interdisciplinarios, en los cuales estaban presentes todos los aspectos que años después vendrían a perfilar el campo (Montero, 1984, 2004). Fue así que desde fines de los años sesenta y durante los setenta, la psicología comunitaria latinoamericana se constituiría como un campo específico de acción profesional orientado por reflexiones éticas explícitas sobre el respeto de los/as otros/as, una alineación política vinculada a la transformación social, una epistemología de la construcción colectiva, una metodología centrada en la participación y una ontología que concibe una sociedad siempre susceptible de crítica y de cambios (Montero, 1984, 2003; Musitu, Herrero, Cantera \& Montenegro, 2004).

\footnotetext{
1 En el año 1966, en la Conferencia de Swampscott, en Boston, Estados Unidos.
}

En el caso de Chile, una profusa labor vinculada al abordaje de la salud mental desde una perspectiva intracomunitaria y poblacional se llevó a cabo en los años sesenta y setenta (Asún, Aceituno, Alfaro, Morales \& Krause, 1993), así como el trabajo de diversas ONG comprometidas con la lucha contra la dictadura militar durante los ochenta. En los noventa, el proceso de restitución del poder institucional civil implicó una rápida vinculación entre los sectores profesionales de la psicología comunitaria y las esferas gubernamentales (Asún \& Unger, 2007), relacionada con la reconstrucción de un sistema político orientado a la re-institución del sistema democrático (Zambrano \& Alfaro, 2007). Desde entonces se concibe que la psicología comunitaria ha alcanzado su máximo nivel de difusión, al instalarse el enfoque social-comunitario en el imaginario de las políticas sociales del país (Asún \& Unger, 2007).

Asún y Vidales (2002, Octubre) consideran como auspicioso el incremento de instancias académicas reflexivas desde perspectivas socio-comunitarias para la superación de las problemáticas psicosociales. Esto, si bien puede ser connotado positivamente, se presenta en un contexto mayor en el que el quehacer de el/la psicólogo/a comunitario/a es delimitado por intereses y agendas político-institucionales que no necesariamente se corresponden ni con la perspectiva del trabajo con comunidades ni con los intereses y necesidades de las mismas (Sánchez Vidal, 2007). Asimismo, enfrentamos el desafío de intervenir en períodos de tiempo acotados, a la luz evaluadora de distintos indicadores de impacto, fijados por los programas sociales (Alfaro, 2000).

Este proceso ha sido apreciado con ambivalente incomodidad por los círculos académicos y profesionales, en tanto las intervenciones se someten a progresivos procesos de normalización y tecnificación, perfilando un modo de hacer difícil de asimilar al espíritu iniciático libertario y utópico de la psicología comunitaria, especialmente al de la psicología comunitaria latinoamericana (Sánchez Vidal, 2007). Krause (2007) señala que el rol del psicólogo/a comunitario/a fomenta la representación de un/a experto/a que brinda apoyo psicosocial desde postu- 
ras asistenciales, las cuales reproducen las perspectivas tradicionales de trabajo clínico en individuos o grupos. A partir de la revisión del enfoque de la psicología comunitaria en artículos de revistas científicas chilenas entre 1993 y 2003, Reyes (2007a) da cuenta de que la mayor parte de las investigaciones e intervenciones publicadas son de tipo asistencial-consultivo y carecen de reflexiones sobre aspectos éticos implicados en los procesos llevados a cabo. Esto plantea una serie de potenciales incongruencias entre los discursos académico-profesionales, epistémico-ideológicos y su relación con las prácticas concretas de la psicología comunitaria (Serrano-García \& Vargas, 1993). Asimismo, esta situación se presenta en un vacío ético institucional, en tanto no existen instancias que normalicen o discutan situaciones de implicancia ética específicas del área, lo que se presenta como una tarea pendiente (Winkler, 2007).

En el marco del proyecto Cuestiones Éticas en la Práctica, Investigación y Formación en Psicología Comunitaria abordamos el campo de la praxis profesional y la ética desde aquello que consideramos relevante al aproximarnos al área y que ha sido relativamente olvidado en las investigaciones al respecto: las voces de los/as usuarios/as de los programas sociales en que participan psicólogos/as comunitarios/as. Hemos pretendido indagar en cómo significan el ejercicio profesional las personas posicionadas en el lugar de usuarios/as de programas sociales públicos y/o privados y qué componentes éticos pueden ser extraídos a partir de estas significaciones. Lo hicimos considerando que los aportes de significados sobre el ejercicio profesional y su ética, desde esta perspectiva, pueden ser muy valiosos para esclarecer el papel que efectivamente desempeñan los/as psicólogos/as comunitarios/as, aportando material para la reflexión.

Para esto, hemos acudido a un concepto productivo, desde nuestra visión, relativo a la construcción de significados en torno a objetos sociales: las Representaciones Sociales (RS). Hemos recurrido, también, a herramientas práctico-conceptuales derivadas del análisis del discurso para apoyar el enfoque adoptado en esta labor.

\section{Orientación Epistémico-Conceptual}

Como una aproximación a la praxis de la psicología comunitaria, contemplamos el esquema de Quintal de Freitas (1994, citado en Montero, 2007) que establece cuatro tipos de prácticas psicológicas a nivel de las comunidades, cada una contribuyente a una identidad disciplinar específica: la psicología en la comunidad (o clínica psicológica inserta en un contexto social), la psicología para la comunidad (o psicología con enfoque individual que asocia bienestar personal y social-comunitario), la psicología de la comunidad (psicólogo/a como activista político) y la psicología con la comunidad (psicólogo/a como catalizador de procesos sociales relevantes para y desde la comunidad). Esta clasificación nos ha servido para comprender los distintos niveles de compromiso involucrados en la praxis socio-comunitaria.

Como objeto de investigación, las RS constituyen una herramienta teórica que permite entender los modos que puede adoptar el pensamiento social (Araya, 2002), centrándose en cómo las personas construyen y son construidas por la realidad social, a través de las dinámicas y contenidos del conocimiento del sentido común (Banchs, 2000). Farr (1984, citado en Araya, 2002) las concibe como sistemas cognoscitivos, teorías o ramas de conocimiento que sirven para la organización de la realidad, aproximación que destaca la cualidad eminentemente cognitiva de las RS. No obstante, su rasgo principal, según Ibáñez (1988, citado en Araya, 2002), es su carácter socialmente constituido y constituyente de los objetos y las relaciones sociales, que conjuga las dimensiones cognitivas y sociales de la construcción de la realidad (Araya, 2002).

Las RS, como núcleos de pensamiento de sentido común que se construyen, desplazan y transforman a través de procesos de comunicación cotidianos (Rodríguez, 2007), contienen componentes simbólicos (de significación y estructuración de la realidad) y prácticos (de orientación de la acción e instrumentalización social del objeto representado) que se distribuyen de manera diversa en la sociedad y por la sociedad (Araya, 2002). Existen diversas aproxima- 
ciones para su estudio, entre ellas, la escuela procesual y la estructural o cognitivista (Araya, 2002). Nuestro enfoque se aproxima a una perspectiva socio-construccionista, en tanto asume el rol relevante del plano simbólico y relacional en la organización de la realidad (Gergen, 1985). La concepción de las RS, enmarcada en este contexto, alude a una narración -representación simbólica colectiva- que emerge en formas estructuradas de conocimiento o pensamiento social, conformando verdaderas teorías de sentido común que permiten describir, clasificar y explicar los fenómenos de la realidad cotidiana con suficiente precisión como para poder desenvolverse en ella sin mayores dificultades.

Afiliamos al esquema estructural de las RS, que se fundamenta en la Teoría del Núcleo Central, de tradición estructuralista (Salkind, 1998). Esta, y aunque parezca paradójico al considerar nuestra adscripción epistemológica, se centra en las funciones cognitivas y recurre a técnicas estadísticas para su reconstrucción. Desde esta perspectiva, las RS se constituyen como una estructura que concentra los elementos de significación más estables (el núcleo figurativo), situándose alrededor los significados más inestables, organizados para concretar, adaptar y proteger de su eventual transformación al núcleo: el sistema periférico. Las RS serían un conjunto de comprensiones globales organizadas por relaciones múltiples que pueden ser de implicación, causalidad o jerarquía, o bien de similitud, equivalencia o antagonismo (Flament, 1994, citado en Banchs, 2000).

No obstante los desarrollos preeminentemente cognitivistas en esta área, Rodríguez (2007) considera que es posible acceder tanto al núcleo figurativo de las $\mathrm{RS}$ como a sus componentes periféricos utilizando procedimientos enfocados en el discurso, atendiendo a sus propiedades simbólicas, expresivas y asociativas. Para esto, recurre a la idea de los themata (Moscovici, 1993, citado en Rodríguez, 2007) como componentes del núcleo: "contenidos potenciales que provienen de la memoria colectiva y el lenguaje, que a su vez impulsan la elaboración de contenidos reales" (Holton, 1985, citado en Rodríguez, 2007, p. 172).

Moscovici (1993, citado en Rodríguez, 2007) considera que el núcleo central de las RS está constituido por "una cadena inicial de pocos themata" (p. 173), identificados como metáforas conceptuales que expresan ciertas implicancias. Rodríguez (2007) detalla, además, otros indicadores discursivos para establecer las jerarquías en la estructura, según su cercanía al núcleo: énfasis, repeticiones, naturalizaciones, explicaciones, asociaciones emocionales, asociaciones conceptuales fuertes y débiles, recurso a fuentes de autoridad y citas sociales.

Como una forma de comprender estos indicadores, que en sí constituyen instancias lingüísticas que están más allá de lo únicamente semántico, implicando cuestiones prosódicas y de contexto (véase Levinson, 1983), hemos integrado los desarrollos del análisis del discurso como una aproximación al lenguaje y sus efectos.

Si bien, como señalan Garay, Íñiguez y Martínez (2005), es difícil hablar de discurso o de análisis del discurso desde una concepción única y unitaria, hacerlo es una forma de atender y remarcar los aspectos constructivos y productivos del uso del lenguaje, de nuestras prácticas lingüísticas, en contraste con la consideración del lenguaje como mera descripción o representación del mundo.

Para detectar los indicadores propuestos por Rodríguez (2007), atendimos a la cualidad performativa del lenguaje, vale decir, a las acciones realizadas por medio del habla (Searle, 1965). Austin (1962, citado en Íñiguez, 2006) sostiene que cuando se habla no solo se expresa un significado, sino que se hace alguna cosa. Esta concepción resalta el componente pragmático de algunos enunciados que, además de su sentido semántico y en asociación al contexto de enunciación y el conocimiento compartido por hablante y oyente, se constituyen en acciones (Grice, 1975, citado en Íñiguez, 2006; Van Dijk, 1984, 1992). Junto a esta, los conceptos de implicatura, presuposición y la noción de indexicalidad (Îniguez, 2006) 
nos orientaron en el texto para atender al sentido de los enunciados en su contexto ${ }^{2}$. En el plano práctico, esto nos llevó a preguntarnos qué se hace y qué se dice cuando se habla, en relación al texto y al contexto, de forma de comprender las RS y su organización. De esta manera, fundamentamos una perspectiva para abordar las RS desde un enfoque estructural, pero atendiendo al discurso como fuente para su reconstrucción, manteniendo afinidad epistémica con el socio-construccionismo.

\section{Método}

\section{Campo de Estudio y Muestreo}

El campo de estudio estuvo compuesto por personas usuarias de programas comunitarios sustentados por organismos públicos o privados en la Región Metropolitana, que han mantenido contacto directo con psicólogos/as comunitarios/as desde su rol profesional, por un período de por lo menos un año.

Inicialmente, exploramos de manera accidental por medio de Internet las organizaciones públicas y ONG que llevan a cabo programas de intervención social, en las cuales se menciona la realización de actividades de carácter comunitario. Recurrimos, luego, a un muestreo por conveniencia (Martín-Crespo \& Salamanca, 2007, Febrero 18), solicitando colaboración para contar con el acceso a beneficiarios/as de sus programas a aquellas organizaciones en que trabajan psicólogos/as comunitarios/ as, asequibles mediante contactos.

\footnotetext{
2 Implicatura es una inferencia pragmática que permite comprender el significado más allá de lo que se dice literalmente. Se compone del significado literal del enunciado, el conocimiento que comparten hablante y oyente, el contexto situacional y la intención del hablante (Grice, 1975, citado en Íñiguez, 2006). Se distingue del término implicancia, que señala el mismo proceso en el orden semántico. La presuposición trata de significados que son asumidos como supuestos en algunas expresiones y sirven para evaluar la verdad o éxito de la oración. La indexicalidad se refiere a ciertos indicadores en la estructura gramatical -las deixis- que enlazan o relacionan el discurso con el contexto (Íñiguez, 2006).
}

Las organizaciones que accedieron a participar desarrollan labores en ámbitos diversos, como reparación de relaciones de abuso por violencia o drogas, promoción de derechos de la infancia y potenciación comunitaria. Dos de ellas dependen de la administración pública para la orientación de sus fines y dos son ONG, todas ellas ubicadas en la Región Metropolitana.

Conformamos cuatro grupos, uno por organismo, en los cuales participaron un total de 32 personas beneficiarias, entre 13 y 90 años: 25 mujeres (22 adultas, 3 adolescentes) y 6 hombres (4 adolescentes y 1 adulto). Todos/as han participado en programas sociales con psicólogos/as comunitarios/as por lo menos durante un año.

\section{Instrumento}

Para recolectar la información empleamos la entrevista participativa (EP), descrita por Montero (2006) como un medio para "conocer las opiniones e ideas de un grupo específico de personas (...) acerca de un tema común, en función de preguntas formuladas por el investigador y respondidas en una conversación general producida y generada por el investigador" (p. 210). La seleccionamos como propicia para la generación y elaboración de relatos a partir de una situación con un grado de estructuración relativa, de manera de posibilitar el acceso a contenidos relevantes para las propias personas, en relación a nuestros objetivos de estudio.

Elaboramos un guión general de entrevista semi-estructurada conformado por tres ejes temáticos: (a) aproximación e inserción de los/as usuarios/as al programa en que participan o han participado y primeros contactos con un/a psicólogo/a comunitario/a, (b) relación establecida con un/a psicólogo/a comunitario/a y (c) especificidades del ejercicio profesional. Para el primer eje fue relevante detectar a lo largo de la EP el conocimiento del programa comunitario, el proceso de inserción y emergencia de la figura de el/la psicólogo/a comunitario/a en este y las expectativas en torno a su rol. Para el segundo fue importante indagar sobre la frecuencia, modo y espacios de contacto, pensamientos, recuerdos, va- 
loraciones y adjetivaciones de la acción de el/la psicólogo/a, y los potenciales procesos de construcción de vínculo y desvinculación con el/la mismo/a. Para el tercero era relevante especificar lo que los/as participantes definirían como el trabajo desarrollado por el/la profesional y las similitudes y/o diferencias de las intervenciones llevadas a cabo por otras disciplinas.

\section{Procedimiento}

Cada institución participante contó con un informe escrito referente a la finalidad de esta investigación y las características de nuestro campo de estudio, indicando el resguardo confidencial del nombre del organismo. De esta manera, procedieron a invitar a las personas asociadas a sus programas a una conversación sobre el trabajo realizado en el lugar. Los detalles del estudio fueron entregados una vez que acudían a la cita. Todas las personas accedieron a participar voluntariamente; el acuerdo fue registrado en un consentimiento informado que explicitaba la posibilidad de abandonar la investigación, si así lo deseaban, la utilización de un seudónimo y la devolución de los resultados, una vez elaborados. En el caso de personas adolescentes, se solicitó también consentimiento escrito de los padres.

Las entrevistas fueron llevadas a cabo por el autor principal de este artículo, grabadas en audio. Tuvieron una duración promedio de una hora y fueron realizadas en las sedes de los programas. Solo una se efectuó en un recinto cercano al hogar de las personas que participaron en la entrevista. En cada grupo participó la totalidad de los/ as invitados/as a la instancia, formándose cuatro grupos según la distribución indicada en la Tabla 1.

\section{Análisis de la Información}

Transcribimos las cuatro entrevistas grupales empleando el Código Jeffersoniano (Antaki \& Díaz, 2006), desarrollado por Gael Jefferson, para registrar contenido, sonidos, variaciones y énfasis presentes en las situaciones usuales de conversación.

Las intervenciones, tanto de los/as informantes como del entrevistador, fueron integradas en una matriz de doble entrada, que contenía las categorías consideradas $a$ priori relevantes para nuestro análisis, a saber (Rodríguez, 2007): metaforizaciones, énfasis, repeticiones, explicaciones, citas sociales, recursos a fuentes de autoridad, naturalizaciones (expresiones que refieren al "ser"), asociaciones emocionales y asociaciones conceptuales fuertes y débiles. Así también, consideramos las implicaturas y presuposiciones pragmáticas para profundizar en el sentido contextual de los enunciados. De esta manera, si bien solo realizamos anotaciones para las intervenciones de las personas participantes, las del entrevistador fueron consideradas para comprenderlas en la situación de diálogo.

A lo anterior añadimos tres ejes de análisis que sirvieron para registrar los elementos éticos presentes en el texto. Lo que hicimos fue describir aquello "correcto"

Tabla 1

Distribución de Participantes por Grupo

\begin{tabular}{ll}
\hline Grupo & Integrantes \\
\hline Entrevista Participativa 1 & 4 mujeres adultas \\
Entrevista Participativa 2 & 20 mujeres adultas \\
Entrevista Participativa 3 & 3 mujeres adolescentes \\
& 3 hombres adolescentes \\
Entrevista Participativa 4 & 1 mujer adulta \\
Total & 1 hombre adulto \\
\hline
\end{tabular}


e "incorrecto" para los beneficiarios/as y las implicancias éticas presentes (valores, principios, reflexiones), a partir de lo emergente en el texto literal o bien en sus implicaturas o presuposiciones.

Consideramos cada intervención según las dimensiones expuestas, registrando los significados implicados en los actos lingüísticos. Reconstruimos el núcleo figurativo de las RS, primero, recolectando las metáforas ingresadas a la matriz y organizándolas por categorías de significado. Luego, considerando la síntesis de los énfasis, repeticiones, naturalizaciones, asociaciones emocionales, asociaciones conceptuales fuertes, además de sus implicaturas y presuposiciones, reconstruimos sus relaciones. Los elementos periféricos fueron abstraídos a partir del análisis y síntesis de las asociaciones conceptuales débiles, citas sociales y el recurso a fuentes de autoridad, además de sus implicaturas y presuposiciones.

Luego de lo anterior, sintetizamos los componentes valóricos y éticos referentes a la praxis de los/as profesionales, a partir de la lectura y sistematización de nuestros registros en la matriz, organizándolos según nivel de abstracción y connotación positiva o negativa.

\section{Resultados}

En este trabajo hemos reconstruido un esquema como aproximación a las $\mathrm{RS}$ sobre la praxis de la psicología comunitaria en organismos públicos y ONG, en la Región Metropolitana. Desde la identificación de algunas valoraciones e implicancias éticas sobre el ejercicio de los/as psicólogos/as, hemos establecido también un esquema general que las organiza.

\section{Representaciones Sociales de la Praxis Comunitaria: "Amigo que Cuida"}

Como actos metafóricos, una serie de enunciados se refieren a la figura de el/la psicólogo/a comunitario/a o a su ejercicio, presentados en la forma de comparaciones (del tipo "como si") o evocaciones. Organizadas como cadenas, pueden ser entendidas como una organización unitaria que constituye el núcleo de la RS, significando las experiencias en torno a la praxis de los/as profesionales.

En la Tabla 2 presentamos las frases y oraciones metafóricas más estables y con un alto potencial de significación extraídas del discurso de los/as participantes.

Luego de reconocer los enunciados metafóricos, los organizamos enlazando múltiples cadenas de metáforas cuyo sentido u objeto de referencia fuera similar. La disposición fue generada por nosotros; sin embargo, el contenido de las metáforas se corresponde con extractos textuales de las entrevistas grupales:

[El/la psicólogo/a comunitario/a] es como cualquier persona. Salía a comprar, como cualquier persona y se acercaba. Se ponía a la altura de una, era como de igual a igual. Es como amistad, como que uno está hablando con una amiga de años. Amistad entre comillas: amigos que siempre están cuidando, sacan información, pero se preocupan. Se terminaba ganando el corazón de a poco. Estando acá, estando en la calle, como estando allá, le puedo contar lo que quiera a la tía. Por ser comunitarios hacen un sacrificio.

Uno no es un pajarito que anda volando solo. De partida, yo siempre volaba con mis propias alas, pero las tías eran las que nos guiaban. $Y$ ahora nos quieren dejar solos y que sigamos nosotros, que nosotros elijamos nuestro camino más que nada. No es que ellas se quieran desapegar de nosotros, pero tienen que enseñar a volar con alas propia. De partida, aquí encontramos el nidito que en mi casa no encontré. El hombro en el que desahogarse (...) el saco de box donde pegar.

$Y$ a veces uno se cansa y ahí están ellas para... Ahi están ellas pa' motivarte y hacerte subir de nuevo. Yo creo que ellas nos están enseñando a poner bien los pies en la tierra.

[Ella luchó y luchó] Yo vi todo el esfuerzo que hizo ella y hasta que por una parte yo me convenci por mí que tenía que estar bien para que mis hijos estuvieran bien. Abrió la mente, es posible salir adelante.

He agradecido que lo que hacen ellas, lo hacen por convicciones, no por llenar su bolsillo solamente. Se ponen la camiseta, estudia por vocación, no por [plata]. 
Tabla 2

Metáforas sobre la Praxis de Psicólogos /as Comunitarios / as Presentes en el Discurso de los /as Participantes

\begin{tabular}{l} 
Expresión Metafórica $^{\text {a }}$ \\
\hline Salía a comprar , como cualquier persona y se acercaba \\
[El/la psicólogo/a comunitario/a es] como cualquier persona \\
Estando acá, estando en la calle, como estando allá, le puedo contar lo que quiera a la tía \\
Psicólogos dejan el camino abierto
\end{tabular}

Así es, ahora te toca a ti seguir

De partida, yo siempre volaba con mis propias alas, pero las tías eran las que nos guiaban. Y ahora nos quieren dejar solos y que sigamos nosotros, que nosotros elijamos nuestro camino más que nada

$Y$, a veces, uno se cansa y ahí están ellas para...

He agradecido que lo que hacen ellas, lo hacen por convicciones propias

Sabe lo que hace

Empezar de cero [tras traslado]

[Tienen] más palabras

A la altura de nosotras

Es como una amistad, como que uno está hablando con una amiga de años

Por ser comunitarios hacen un sacrificio

Se ponía a la altura de una (...) era como de igual a igual

No es que ellas se quieran desapegar de nosotros, pero tienen que enseñar a volar con alas propias

Ahí están ellas pa' motivarte y hacerte subir de nuevo

De partida, aquí encontramos el nidito que en mi casa no encontré

Se ponen la camiseta

Donde manda capitán, no manda marinero

Estudia por vocación, no por [plata]

Pero en algún momento igual se dejarán caer, porque, no sé, no se olvidan los lazos de un día para otro

El hombro en el que desahogarse (...) el saco de box donde pegar

Susana, EP1:165

Susana, EP1:165

David, EP3:692

Renato, EP4:324

Renato, EP4:326

David, EP3:704

Karen, EP3:615

David, EP3:632

Tania, EP3:54

Esperanza, EP1:369

Renato, EP4:74

Esperanza, EP1:248

Esperanza, EP1:239

Lía, EP1:453

Margarita, EP1:249

Karen, EP3:696

David, EP3:616

David, EP3:659

Renato, EP4:308

Margarita, EP1:355

Margarita, EP1:326

Karen, EP3:628

David, EP3:661

Margarita, EP1:232

Margarita, EP1:167

Uno no es un pajarito que anda volando solo

Renato, EP4:317

Psicólogos abren las puertas y nos dejan ahí

Yo creo que ellas nos están enseñando a poner bien los pies sobre la tierra

Carmen, EP3:702

Es posible salir adelante

Margarita, EP1:228

Se terminaba ganado el corazón de a poco

Tania, EP3:192

Amistad entre comillas

Renato, EP4:232

Amigos que siempre están cuidando, sacan información, pero se preocupan

Renato, EP4:232

Después de ser psicólogo es tu amigo

Renato, EP4:210

[Ella luchó y luchó] Yo vi todo el esfuerzo que hizo ella y hasta que por una parte yo me convencí por mi que tenía que estar bien para que mis hijos estuvieran bien

Susana, EP1:227

a Las aclaraciones entre [] pretenden completar el sentido pragmático de estas.

b Luego del seudónimo, EP significa entrevista participativa, seguido por el número de su identificador, según la secuencia en que se realizó. Luego de los dos puntos se indica la intervención en la que emerge la metáfora. 
Sabe lo que hace, [tiene] más palabras.

[Pero] donde manda capitán, no manda marinero, [y hay que] empezar de cero [tras traslado]. Pero en algún momento igual se dejarán caer, porque, no sé, no se olvidan los lazos de un día para otro. Después de ser psicólogo, es tu amigo.

[Los] psicólogos abren las puertas y nos dejan ahí, [los] psicólogos dejan el camino abierto. Así es, ahora te toca a ti seguir.

Es posible apreciar que el conjunto de metáforas que componen el núcleo figurativo de las RS da cuenta de un/a psicólogo/a disponible e integrado/a en los espacios cotidianos de la comunidad o localidad, con un estilo de relación establecida de "igual a igual". Las respuestas de los/as participantes simbolizan una relación de "amistad", cuyo fundamento se centra en el cuidado de el/la beneficiario/a. Esto es sintetizado en la significación de el/la psicólogo/a comunitario/a como un/a "amigo/a que cuida".

La acción profesional es construida como un acompañamiento y como la preparación para cuando el/la psicólogo/a no se encuentre presente. La preparación, desde esta perspectiva y con un sentido figurativo, corresponde a un acto de pre-parar, vale decir, generar condiciones para que el/la beneficiario/a logre cierta autonomía, para "poner bien los pies en la tierra" o aprender "a volar con alas propias". Por ejemplo, la siguiente cita refiere la relación entre una acción de cuidado personal y la influencia de la psicóloga:

Yo ahora estoy siguiendo un tratamiento, porque antes yo era de que no, de que ir al médico no, de tomar pastillas no, pero, o sea, igual yo vi todo el esfuerzo que hizo ella y hasta que por una parte yo me convencí por mi de que tenía que estar bien para que mis hijos estuvieran bien. (Susana, EP1:227)

La "amistad", expresada como la vivencia de un vínculo cercano que posibilita la manifestación de sentimientos íntimos, genera una tensión entre la pérdida del vínculo y la aspiración de que este permanezca.

Por otra parte, reiteradamente encontramos distinciones entre la labor desarrollada por psicólogos/as en programas sociales y la clínica, representada como potencialmente amenazante y menos acogedora, en tanto se vincula mayormente con los mecanismos institucionales de regulación o sanción y asociada, en ocasiones, con el actuar médico; por ejemplo:

Entonces, es muy diferente a la psicóloga de allá, porque un día me dijo, la de acá me dijo "Es que si tú estás demasiado mal", me dijo, "no puedes estar cuidando dos niños" (...) Yo todas las cosas que hacía eran por los chiquillos po', o sea, si yo ya no estaba intentando más suicidarme era por ellos po', y que me los quitaran, ¿Qué iba a hacer yo? Nada. (Susana, EP1:400-404)

Respecto a la labor comunitaria, encontramos distintas explicaciones causales referentes al proceso de construcción de la relación, que dan cuenta de una secuencia recursiva cuyos componentes principales son construcción de confianza y afecto, el quiebre del vínculo en relación a circunstancias externas (término del programa, desplazamiento del profesional a otras zonas, rotación) y el rechazo inicial a los/as nuevos/as profesionales:

Pero además de eso también están los cambios bruscos que de repente te cambian el monitor; $y$ es difícil acostumbrarse al sistema de tener otra persona. (Karen, EP3:570)

El rol profesional es difuso y se confunde inicialmente con otros agentes que participan en las intervenciones (voluntarios, trabajadores sociales, educadores); sin embargo, se atribuye cualidades particulares a los/as psicólogos/as, relacionadas específicamente al establecimiento del vínculo. Las personas entrevistadas reconocen una serie de habilidades de escucha y empatía y otras de carácter asistencial, que representan al profesional como componente relevante de la red de apoyo afectivo y como agente vinculante con otras redes de apoyo social, desde una praxis orientada a la ayuda ante necesidades afectivo-informativo-materiales.

En la Figura 1 representamos gráficamente la síntesis de las RS acerca del ejercicio profesional de los/as psicólogos/as comunitarios/as desde la perspectiva de usuarios y usuarias. Los elementos constituyentes del núcleo figurativo están ubicados al centro de la figura.

El núcleo figurativo está compuesto de dos movimientos o tensiones organizadas 


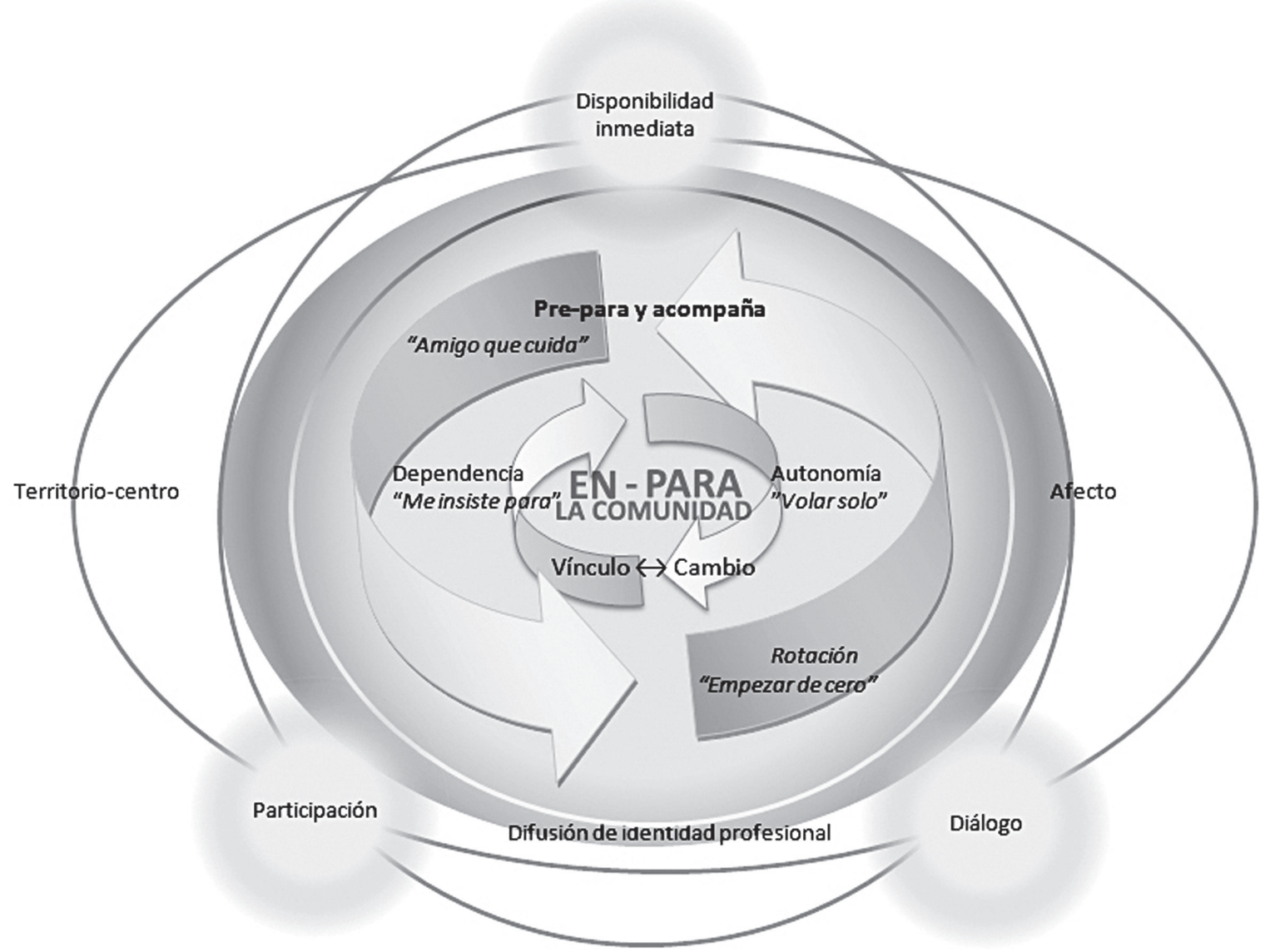

Figura 1. Representaciones sociales del ejercicio de la psicología comunitaria desde la perspectiva de los/as usuarios/as.

dialécticamente. El primero, más al centro, consiste en la representación de las acciones concebidas como insistencia. La expresión "me insiste para" representa la percepción de la persistencia y esfuerzo de el/la psicólogo/a para generar algún cambio, de manera directiva y considerando lo que percibe como bienestar para el/la beneficiario/a. Este movimiento genera dependencia de la figura del psicólogo, tensionándose con la exposición discursiva por parte de el/la psicólogo/a comunitario/a de la necesidad de desarrollar autonomía, lo que es representado metafóricamente por los/as beneficiarios/as como "volar solo". Ambos movimientos se integran y cada acto incluye implícitamente su opuesto, vale decir, en el momento en que el psicólogo expone la necesidad de desarrollar autonomía, genera dependencia, considerada como una fase previa al logro de la autonomía. Asimismo, ambos procesos subyacen al establecimiento del vínculo entre psicólogo/a-beneficiario/a, que sería aquello que posibilita el cambio. El cambio, en este sentido, es entendido como la modificación de patrones de comportamiento, pero no considera una transformación orientada hacia una autonomía plena, en el sentido de toma de poder sobre las decisiones o la autodeterminación. Más bien, la dependencia de el/la profesional promueve la dependencia; y la orientación hacia la autonomía se realiza de un modo tal que también actúa, implícitamente, promoviendo sumisión.

En un nivel superior se sitúa un segundo movimiento compuesto por dos fases. La primera constituye la percepción del rol del psicólogo/a como un "amigo que cuida". El vínculo posee una funcionalidad específica, 
promoviendo el bienestar de el/la usuario/a. La segunda fase surge por la rotación profesional en los programas sociales que provoca la sensación de pérdida del vínculo y el inicio de un proceso de duelo, que fortalece la imagen de el/la psicólogo/a como "amigo/a”. A la vez, la alta rotación profesional genera la sensación de tener que "empezar de cero", recurrentemente. La actividad de el/la psicólogo/a es representada como la de alguien que "pre-para" y acompaña: "pre-para", pues actúa para que las personas logren desarrollar algún grado de autonomía; y acompaña, pues es visto/a como alguien cercano, receptivo y vinculado horizontalmente. Los/as usuarios/as construyen el alejamiento de el/la profesional como una pérdida afectiva, requiriendo esfuerzos socio-afectivos para re-vincularse con un/a nuevo/a agente.

Como sistema periférico, tres círculos en la Figura 1 representan los ejes de la praxis comunitaria: participación, diálogo y disponibilidad inmediata. La participación contempla planificar y desarrollar acciones según criterios establecidos por los/as beneficiarios/as, principalmente en la realización de talleres y actividades formativas o psicoeducación. El diálogo, en tanto, es el medio de relación privilegiado, distinguiéndose de prácticas como la imposición de contenidos temáticos y la indicación de actuar de determinada forma. La disponibilidad inmediata se refiere a la valoración y expectativa de tener acceso a el/la psicólogo/a en todo momento y espacio.

Dos circunferencias cruzan los ejes de acción y envuelven al núcleo central, representando dos movimientos más que caracterizan la praxis: el afecto en el vínculo y la constitución del espacio de intervención. El afecto es producto de la construcción en el tiempo y el espacio de la relación con el o la profesional y caracteriza todos los actos que desarrolla. Si bien no existe consenso en que este sea recíproco, sí se establece que los beneficiarios organizan la relación en torno a su presencia, lo que justifica las imágenes de permanencia del vínculo tras la finalización de los programas.

El reconocimiento de la especificidad profesional de el/la psicólogo/a es inicialmente difuso, distinguiéndose solo al establecer vínculos individuales entre profesional-beneficiario/a y reconociendo que en las intervenciones sociales participan otros profesionales y para-profesionales.

El espacio de intervención es representado por una dicotomía territorio-centro. Las acciones de el/la profesional, desarrolladas en un encuadre local amplio y al mismo tiempo en un centro (sitio físico de la organización-institución de la cual depende el/la psicólogo/a), son valoradas como espacio institucional y significadas de manera particular como experiencias afectivas positivas, que representan un lugar que homogeneiza la posibilidad de acceso a los programas.

Si bien la información recogida es insuficiente para la reconstrucción de un esquema abarcador de las RS, podemos aproximar que el trabajo comunitario, en la praxis, se centra en la labor con individuos, distinguiéndose del trabajo clínico en la utilización de estrategias de acompañamiento y apoyo sistemáticos, constantes y siempre disponibles y en la apertura o desplazamiento del encuadre hacia el espacio social y físico en que habitan cotidianamente las personas. Así, las ideas de dependencia y autonomía apuntan al fortalecimiento del vínculo generado con individuos, para potenciar su desarrollo, perdiéndose la comunidad como objeto/sujeto potencial para generar cambios. Si bien existen intervenciones grupales, estas son complementarias a la labor individual "en sesiones", centrando el foco en el proceso del individuo en el grupo y no primordialmente del grupo en la comunidad.

\section{Aspectos Éticos: Lo Correcto y Lo Incorrecto en el Ejercicio Profesional}

Respecto de los componentes éticos de la praxis, distintas prácticas son connotadas implícitamente por los/as beneficiarios/as como correctas o incorrectas, de acuerdo a sus cánones valóricos y culturales. Esto lleva a establecer una serie de valores y prácticas reconocidos como adecuados y vivenciados positivamente, y otros, desde la vivencia negativa, connotados como inadecuados.

La Figura 2 grafica en un sistema de ejes cartesianos los aspectos correctos e in- 
correctos, tanto en la relación profesional como en el ejercicio profesional de psicólogos/as comunitarios/as, desde la perspectiva de los/as usuarios/as.

Como es posible apreciar, los/as receptores/as de intervenciones desde la psicología comunitaria reconocen una serie de prácticas que consideran adecuadas e inadecuadas, fundamentadas principalmente en su experiencia afectiva. Clasificamos las prácticas adecuadas en cuatro niveles (arriba), según su grado de abstracción: principios, valores, prácticas generales y prácticas específicas, cada uno correspondiente a una columna. En el eje central situamos aquellos componentes que pueden ser adjetivados como principios de la praxis: reconocimiento del valor de la persona, respeto, compromiso, participación, autonomía y perseverar e insistir. En el segundo nivel puede reconocerse, por ejemplo, la flexibilidad, humildad, sistematicidad y creatividad. En el tercer nivel encontramos como prácticas generales connotadas positivamente el acercamiento de el/la profesional a los hogares, la calidez en la acogida, una disposición a mantener el vínculo y transmitir una perspectiva positiva, entre otras. En el cuarto nivel ubicamos prácticas más específicas, también consideradas positivas: entregar apoyo material, dar el número de teléfono, disponibilidad horaria y establecer contacto físico, por ejemplo.

En la sección inferior agrupamos aquellos aspectos vivenciados de manera negativa, sin organización, relacionados al ámbito

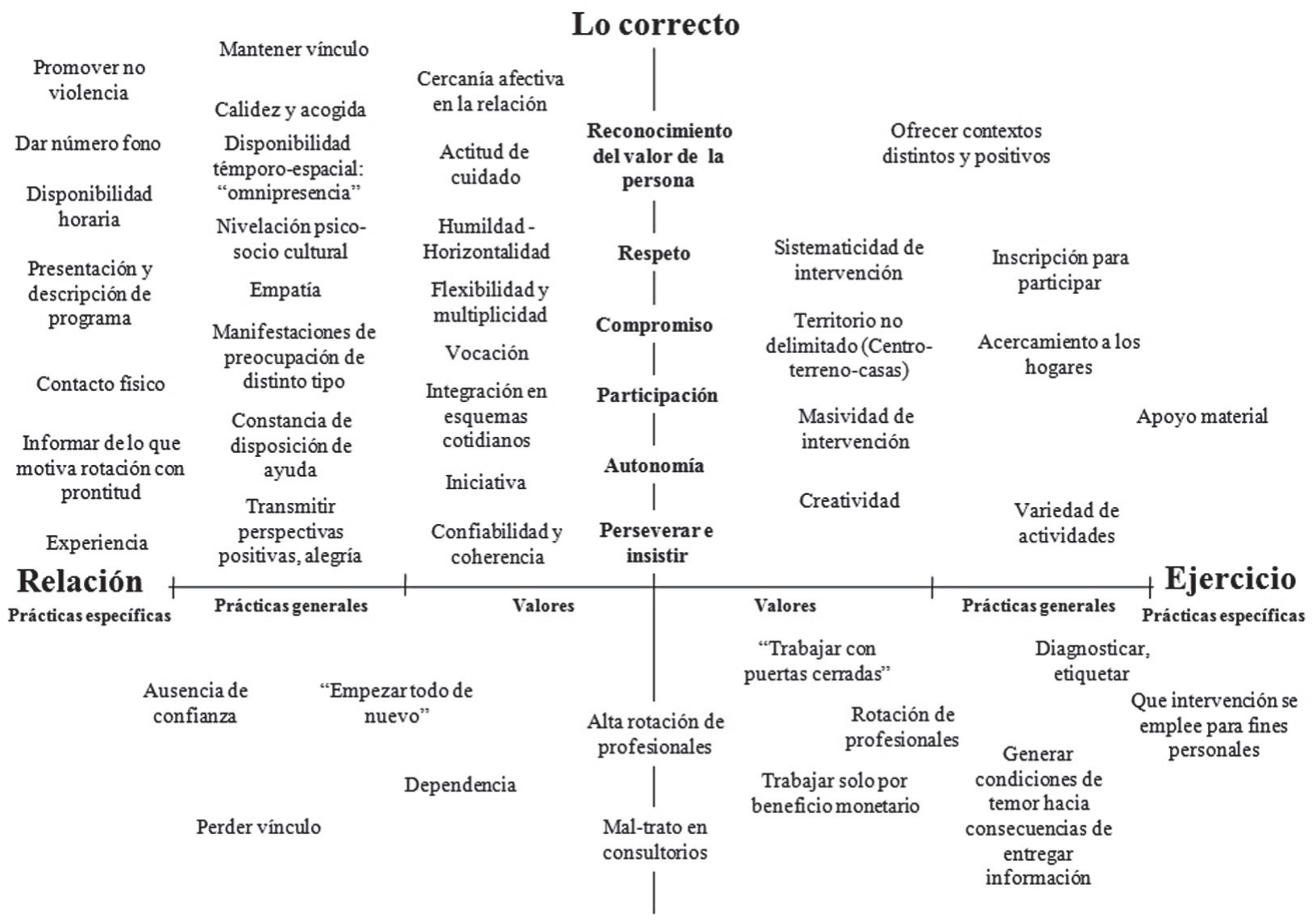

\section{Lo incorrecto}

Figura 2. Lo correcto y lo incorrecto en el ejercicio profesional. 
relacional o del ejercicio. En la Figura 2 se aprecia que obtuvimos menor cantidad de información a este respecto y que se repiten algunos conceptos o ideas que componen las RS del ejercicio profesional de la psicología comunitaria; por ejemplo, la crítica a la alta rotación de profesionales, asociada a la pérdida del vínculo.

\section{Discusión}

La reconstrucción de las RS del ejercicio profesional en psicología comunitaria muestra una praxis distinta al trabajo comunitario comprometido con la transformación social, coincidiendo con los resultados obtenidos por Krause (2007) y Reyes (2007a), así como con los análisis de Asún y Unger (2007) y Sánchez Vidal (2007) sobre las condiciones actuales de la disciplina. Divergentemente a lo esperable, según lo expuesto por Asún y Vidales (2002, Octubre), pareciera que los enfoques que trascienden al individuo y las técnicas de intervención fundamentadas en la investigación-acción no participan en la construcción de significados sobre la praxis profesional. Este contexto pareciera ofrecer la posibilidad y fundamentar la necesidad de llevar a cabo un esfuerzo reconstructivo de la identidad profesional, o bien, de reconceptualización sobre la actividad disciplinar.

Desde la categorización de Quintal de Freitas (1994, citado en Montero, 2007), el ejercicio reconstruido desde la perspectiva de los/as beneficiarios/as se sitúa en un continuo entre ser un/a "psicólogo/a en la comunidad" y un/a "psicólogo/a para la comunidad", articulándose como alguien disponible que compensa las necesidades de apoyo y/u orientación de las personas con quienes trabaja.

Junto a la construcción del profesional como un "amigo que cuida", su actividad se centra en la preparación para el desarrollo de autonomía. Consideramos que este acompañamiento tiende a reproducir, paradojalmente, la dependencia. No obstante, si se nos permite establecer que el trabajo comunitario se desarrolla principalmente en sectores de múltiples precariedades socio-materiales (Montero, 2003), sería posible comprender y justificar esta acción en la medida en que, desde la información otorgada por el núcleo figurativo de las RS sobre la praxis, podría promover progresivamente el fortalecimiento individual. En las metáforas que emplean los/as participantes para representar la labor del psicólogo, "un pajarito" puede simbolizar desvalimiento, soledad, fragilidad e infantilismo, junto a la necesidad de cuidado, protección, orientación, acompañamiento, guía y apoyo constante para lograr finalmente "volar solo". El vínculo con el profesional comunitario es representado, entonces, como una instancia "re-paradora" de experiencias personales previas, en que lo afectivo constituye un componente relevante.

Aun cuando lo anterior puede implicar una crítica a la especificidad profesional de la psicología comunitaria, en tanto la alusión de las RS de los/as usuarios/as a la aproximación individualizada rompe referencias con el fortalecimiento comunitario como forma de promover la transformación social, es necesario rescatar que el valor asignado desde ellos/as es positivo y mantiene cierto campo de diferenciación de otras áreas de la psicología, como la psicología clínica. Una mayor apertura, tanto al campo como a lo que podría denominarse adaptación ideo-cultural, o adaptación a los modos idiosincrásicos y culturales de las personas de concebir sus problemas y situaciones cotidianas, parecen ser algunas cualidades que la distinguen de esta última.

Desde otro enfoque, los resultados señalan al cuidado como componente central de las RS que, aunque orientado al empoderamiento -individual-, conlleva un doble juego de crecimiento e invalidación, en tanto implica cierta inferioridad o necesidad de apoyo de quien actúa como beneficiario/a. Lo mismo acontece en la dinámica de transmisión de la imagen de el/la psicólogo/a como experto/a formado en ciertas áreas de relación, que lo objetiva como una figura estable y con ciertas habilidades que ubican a los/as beneficiarios/as en el polo menos valorado del continuo saber-no saber. Sin embargo, y al considerar las nociones de anclaje de las RS (Araya, 2002), emerge una perspectiva distinta: podríamos suponer, a partir de algunos estudios (véase Reyes, 2007b), que la psicología clínica es el elemento vin- 
culante -ancla- para las RS de la psicología comunitaria. Ello puede explicar, hasta cierto punto, la asociación y énfasis técnico en lo profesional (la valoración de las habilidades relacionales, por ejemplo). Sin embargo, la psicología comunitaria comporta elementos diferenciadores del ejercicio clínico en las RS, que le confieren, como hemos mencionado, cierto estatus exclusivo que se aproximaría más al tipo de intervención acorde a necesidades definidas por las mismas personas.

En este contexto parece útil interpretar el asistencialismo, presente en el modo de operación, como respuesta a ciertas demandas afectivo-materiales y situacionales de las personas. Quizás sea posible entenderlo como una fase previa -ineludible- para el desarrollo de líneas de acción posteriores orientadas a modificaciones estructurales. Así, podemos proponer una formación profesional que incluya nociones sobre las condiciones y expectativas concretas de los/as beneficiarios/as y una propuesta intervencionista gradual, que evolucione desde el asistencialismo hacia el acompañamiento y, desde allí, hacia el empoderamiento y/o el fortalecimiento.

Asimismo, podemos considerar que los programas, focalizados y delimitados temporalmente, pierden sentido si los desarrollos logrados se vinculan a la presencia de profesionales que, al rotar, implica "empezar de cero". Esto lleva a la necesidad de evaluar el diseño de políticas públicas para minimizar este efecto negativo.

Por otra parte, las afirmaciones que consideran un incorrecto ejercicio profesional -"trabajar con puertas cerradas" y "diagnosticar, etiquetar"- plantean un nuevo e interesante desafío. Si bien podemos estar de acuerdo con que "etiquetar" corresponde a una mala praxis, "trabajar con puertas cerradas" y "diagnosticar" corresponden a un ejercicio profesional técnica y éticamente apropiado en el caso de la psicología clínica. Hipotéticamente podría postularse que ello, de alguna manera, presupone -desde la perspectiva de nuestros/as participantesque una praxis clínica técnica y éticamente correcta sería una praxis comunitaria técnica y éticamente inadecuada.

\section{Conclusiones}

Consideramos que a través de esta investigación ha sido posible cubrir las acciones propuestas por los objetivos. De esta manera, podemos señalar que la labor comunitaria se reconoce desde los/as usuarios/as como orientada al fortalecimiento y empoderamiento gradual, aun cuando en sus abordajes de las problemáticas psicosociales prevalezca una perspectiva asistencial, enlazada a la reproducción de un vínculo de dependencia de el/la profesional. Esta dependencia no solamente es práctica sino, hasta cierto punto, también afectiva, pero se presenta como un medio operativo en los/as beneficiarios/as para lograr desarrollarse y superar en algún nivel sus condiciones problemáticas.

La cantidad de mujeres que ha participado en el estudio, aunque dependiente de las cualidades y limitaciones del muestreo realizado, es un buen indicador para considerar cuestiones relativas al género, tanto en la investigación como en la diversidad de aspectos asociados que permean el trabajo de el/la profesional. No obstante, las limitaciones de esta investigación, especialmente en cuanto al tipo de muestreo realizado y la distribución de participantes por grupos, podrían ser superadas en futuras investigaciones.

En el plano de lo ético y lo relacional, la cercanía, compañía y disponibilidad, las posibilidades de encuentro y la sistematicidad en el trabajo, siempre orientadas y centradas en la persona usuaria y sus necesidades, parecen ser los aspectos valorados de la praxis comunitaria, distinguiéndose de otros ejercicios disciplinares y perfilando una identidad profesional identificada con las necesidades concretas de las personas. Si bien reconocemos que existen importantes desafíos si la disciplina pretende actualizar su ideario fundacional, especialmente en lo relativo a lo político y metodológico, su acción tal y como es representada por los/as usuarios/as -según los resultados de esta investigación- es valorada e integrada como un recurso importante para el desarrollo psicosocial. 


\section{Referencias}

Alfaro, J. (2000). Discusiones en psicología comunitaria. Santiago, Chile: Universidad Diego Portales.

Antaki, Ch. \& Díaz, F. (2006). El análisis de la conversación y el estudio de la interacción social. En L. Íniguez (Ed.), Análisis del discurso. Manual para las ciencias sociales ( $2^{\mathrm{a}}$ ed., pp. 129-142). Barcelona: Editorial UOC.

Araya, S. (2002). Las representaciones sociales: ejes teóricos para su discusión (Cuaderno $\mathrm{N}^{\circ}$ 127). Extraído el 23 Junio, 2008, del sitio Web de la Facultad Latinoamericana de Ciencias Sociales, Sede Costa Rica:http://www.flacso.or.cr/fileadmin/ documentos/FLACSO/Cuaderno127.pdf

Asún, D., Aceituno, R., Alfaro, J., Morales, G. \& Krause, M. (1993). La psicología comunitaria en Chile: análisis de sus características y perspectivas. En E. Sánchez \& E. Wiesenfeld (Eds.), Psicología social comunitaria. Contribuciones latinoamericanas (pp. 151-187). Caracas: Editorial Tropikos.

Asún, D. \& Unger, J. (2007). Una visión regional de la institucionalización de la psicología (social) comunitaria en Chile. En A. Zambrano, G. Rozas, F. Magaña, D. Asún \& R. Pérez-Luco (Eds.), Psicología comunitaria en Chile: evolución, perspectivas y proyecciones (pp. 213-226). Santiago, Chile: RIL Editores.

Asún, M. \& Vidales, A. (2002, Octubre). La psicología comunitaria a la luz de la historia. Ponencia presentada en el III Encuentro de Estudiantes en Psicología Comunitaria, Valparaíso, Chile.

Banchs, M. A. (2000). Aproximaciones procesuales y estructurales al estudio de las representaciones sociales. Papers on Social Representations, 9, 3.13.15. Extraído el 23 Junio, 2008, de http://www. psr.jku.at/PSR2000/9_3Banch.pdf

Dokecki, P. R. (1992). On knowing the community of caring persons: A methodological basis for the reflective-generative practice of community psychology. Journal of Community Psychology, 20, 26-35.

Garay, A., Íñiguez, L. \& Martínez, L. M. (2005). La perspectiva discursiva en psicología social. Subjetividad y Procesos Cognitivos, 7, 105-130.

Gergen, K. J. (1985). The social constructionist movement in modern psychology. American Psychologist, 40, 266-275.

Íñiguez, L. (2006). El lenguaje en las ciencias sociales: fundamentos, conceptos y modelos. En L. Íñiguez (Ed.), Análisis del discurso. Manual para las ciencias sociales ( $2^{\mathrm{a}}$ ed., pp. 47-87). Barcelona: Editorial UOC.

Krause, M. (2007). Discusión crítica de la práctica de intervención psicológico-comunitaria en Santiago de Chile. En J. Alfaro y H. Berroeta (Eds.), Trayectoria de la psicología comunitaria en Chile: Prácticas y conceptos (pp. 73-96). Valparaíso, Chile: Universidad de Valparaíso.

Levinson, S. (1983). Pragmática. Barcelona: Teide.

Martín-Crespo, M. C. \& Salamanca, A. B. (2007, Febrero 18). El muestreo en la investigación cualitativa. Nure Investigación, 27, Artículo 4. Extraído el 20 Mayo, 2009, de http://www.nureinvestigacion. es / F I CHEROS_ADMINISTRADOR/F_ METODOLOGICA/FMetodologica_27.pdf
Montero, M. (1984). La psicología comunitaria: orígenes, principios y fundamentos teóricos. Revista Latinoamericana de Psicología, 16, 387 400.

Montero, M. (2003). Teoría y práctica en psicología comunitaria. La tensión entre comunidad y sociedad. Buenos Aires: Paidós.

Montero, M. (2004). Introducción a la psicología comunitaria. Buenos Aires: Paidós.

Montero, M. (2006). Hacer para transformar: el método en psicología comunitaria. Buenos Aires: Paidós.

Montero, V. (2007). Nuevos enfoques y prácticas de psicología comunitaria para el desarrollo. Extraído el 21 Mayo, 2008, del sitio Web de la Facultad de Psicología de la Universidad Nacional Mayor de San Marcos: http://www.unmsm.edu. pe/psicologia/documentos/documentos2007/ libro\%20eap/11LibroEAPMontero.pdf

Musitu, G., Herrero, J., Cantera, L. \& Montenegro, M. (2004). Introducción a la psicología comunitaria. Barcelona: Editorial UOC.

Reyes, M. I. (2007a). Orientaciones ético-valóricas de la psicología comunitaria en Chile: análisis descriptivo de los artículos publicados en revistas nacionales entre 1993 y 2003. En J. Alfaro \& H. Berroeta (Eds.), Trayectoria de la psicología comunitaria en Chile: Prácticas y conceptos (pp. 109-148). Valparaíso, Chile: Editorial Universidad de Valparaíso.

Reyes, M. I. (2007b). La imagen de los / as psicólogos / as en los medios de comunicación: representaciones sociales del ejercicio y la conducta ética profesional en el contexto chileno. Tesis no publicada para optar al grado de Magíster en Psicología Clínica, Universidad de Santiago de Chile, Santiago, Chile.

Rodríguez, T. (2007). Sobre el estudio cualitativo de la estructura de las representaciones sociales. En T. Rodríguez \& M. García (Eds.), Representaciones sociales. Teoría e investigación (pp. 157-188). Ciudad de México: Editorial Universidad de Guadalajara.

Salkind, N. (1998). Métodos de investigación. Ciudad de México: Prentice Hall.

Sánchez Vidal, A. (2007). La psicología comunitaria chilena en la hora de la institucionalización: eclecticismo teórico, compromiso práctico y cuestiones éticas. En A. Zambrano, G. Rozas, F. Magaña, D. Asún \& R. Pérez-Luco (Eds.), Psicología comunitaria en Chile: evolución, perspectivas y proyecciones (pp. 23-54). Santiago, Chile: RIL Editores.

Searle, J. R. (1965). ¿Qué es un acto de habla? En L. Valdés (Comp., 1991), La búsqueda del significado (pp. 431-448). Madrid: Tecnos.

Serrano-García, I. \& Vargas, R. (1993). La psicología comunitaria en América Latina. Estado actual: controversias y nuevos derroteros [Versión electrónica]. Papeles del Psicólogo, 55, 41-47.

Van Dijk, T. (1984). Texto y contexto. Semántica y pragmática del discurso. Madrid: Cátedra.

Van Dijk, T. (1992). La ciencia del texto ( $3^{\mathrm{a}}$ ed.). Barcelona: Paidós.

Winkler, M. I. (2007). Cuestiones éticas en psicología comunitaria: dudas en la praxis. En J. Alfaro \& H. Berroeta (Eds.), Trayectoria de la psicología 
comunitaria en Chile: Prácticas y concepto (pp. 373-400). Valparaíso, Chile: Editorial Universidad de Valparaíso.

Zambrano, A. \& Alfaro, J. (2007). Desarrollo y estado actual de la psicología comunitaria en Chile: trayectorias, tensiones y perspectivas. En J. Alfaro \& H. Berroeta (Eds.), Trayectoria de la psicología comunitaria en Chile. Prácticas $y$ conceptos (pp. 149-158). Valparaíso, Chile: Editorial Universidad de Valparaíso.

Fecha de recepción: Marzo de 2009.

Fecha de aceptación: Noviembre de 2009. 